At the NPL, acknowledgement is given to Dr R. Morrell for his advice and calculations relating to the problem of deformation of glass under stress, to $\mathrm{Mr}$ $\mathrm{K}$. Lindsey for the concept of pivoted cylinders and for testing and coating the mirrors and to $\mathrm{Mr} \mathrm{V}$. W. Stanley for general discussions about the camera design.
References

BUTLER, D. W. (1974). In preparation.

Franks, A. (1958). Brit. J. Appl. Phys. 9, 349-352.

LiNDSEY, K. (1973). Proc. Mullard Space Science Lab. Conf Astrophys. Appl. X-ray Optics. In the press.

Rosenbaum, G., Holmes, K. C. \& WiTZ, J. (1971). Nature, Lond. 230, 434-437.

J. Appl. Cryst. (1974). 7, 125

\title{
The Design of X-ray Mirror Optics for Small-Angle Scattering Cameras
}

\author{
By C. A. Wallace and P. A. Wallace \\ Neutron Division, Marconi-Elliott Avionic Systems Limited, Elstree Way, Borehamwood, Herts., England
}

\begin{abstract}
A number of small-angle scattering cameras make use of X-ray focusing mirrors, such as the doublemirror camera of A. Franks [Proc. Phys. Soc. (1955). B 68, 1054] and the mirror-monochromator system of H. E. Huxley \& W. Brown [J. Mol. Biol. (1967). 30, 383]. Among the factors limiting the angular resolution, which determines the maximum distance over which long-range order can be detected by X-ray diffraction, are the finite focus of the X-ray source and the inherent aberrations of the X-ray lenses. In the Franks camera optimum focusing is achieved when the mirror is exactly halfway between source and film. Thus maximum angular resolution is attained in only one plane at a time. In the Huxley camera the mirror is usually placed as close as possible to the source in the interest of a high aperture but at the expense of large aberrations. Thus the very high angular resolution in the focusing of the crystal monochromator is accompanied by poor resolution in the perpendicular plane. Theoretical calculations of the aberrations in these X-ray lens systems are presented in which the effects of variation in the positions and lengths of the mirrors can be predicted. A very simple modification to the conventional design of the X-ray focusing mechanism, a four-point bending device, can be shown to reduce the aberrations significantly and/or to allow mirrors of greater aperture to be employed. The design parameters required to achieve minimum aberrations in both focusing planes are established for both Franks and Huxley type cameras.
\end{abstract}

J. Appl. Cryst. (1974). 7, 125

\section{Influence des Interfaces Rugueux sur la Réflexion Spéculaire des Rayons X}

\author{
Par P. Croce et L. Névot \\ Institut d'Optique, Laboratoire associé du C.N.R.S., Faculté des Sciences, 91 Orsay, France
}

(Reçu le 22 octobre 1973, accepté le 30 octobre 1973)

\begin{abstract}
The study of specular reflexion or scattering of soft X-rays from rough surfaces is greatly simplified if we suppose that X-rays are not perturbed inside the matter. This simplifying assumption appears to be valid in the higher range of grazing angles, such as $\theta \gtrsim 4 \theta_{c}$ where $\theta_{c}$ represents the critical angle of total reflexion. In this case, the Fresnel reflexion coefficient in the specular direction for a plane surface is proportional to $1 / \sin ^{4} \theta$; moreover we can account for the roughness of the surface, in an equivalent way, either by using the well-known attenuation factor $\exp \left\{-16 \pi^{2} / \lambda^{2}\left\langle z^{2}\right\rangle \sin ^{2} \theta\right\}$ or by replacing the rough surface with a transition layer in which the variations of the refractive index agree with the error function. But, in the smaller-angle range, $\theta \leqslant \theta_{c}$, the second model seems to be more convenient. With models with one or two rough surface layers, an attempt is made to find an interpretation of the reflexion curve obtained with $1.5405 \AA$ X-rays on a sample of germanium monocrystal.
\end{abstract}

L'intérêt de l'utilisation des rayons $\mathrm{X}$ et des neutrons pour l'étude de la matière est dû surtout à la faible interaction de tels rayonnements avec la matière. En effet, la perturbation introduite, en général, par les interfaces et les diffusions multiples, est souvent négligeable, ce qui rend plus aisée l'interprétation des résul- 